\title{
Applicability of Universal Thermal Climate Index (UTCI) in occupational heat stress assessment: a case study in brick industries
}

\author{
Javad VATANI ${ }^{1}$, Farideh GOLBABAEI ${ }^{2} *$, Somayeh Farhang DEHGHAN ${ }^{2}$ and Azam YOUSEFI ${ }^{3}$ \\ ${ }^{1}$ Department of Occupational Health, School of Public Health, International Campus, Tehran University of \\ Medical Sciences, Iran \\ ${ }^{2}$ Department of Occupational Health, School of Public Health, Tehran University of Medical Sciences, Iran \\ ${ }^{3}$ Department of Medicinal Plants, School of Agriculture, University of Applied Science and Technology, Iran
}

Received April 4, 2015 and accepted July 23, 2015

Published online in J-STAGE August 28, 2015

\begin{abstract}
The present study aimed to investigate the applicability of Universal Thermal Climate Index (UTCI) as an innovative and science-based index in public health researches, in occupational heat stress assessment. All indoor and outdoor workers (200 people) of Brick industries of Shahroud, Iran participated in the research. First, the environmental variables such as air temperature, wet-bulb temperature, globe temperature, air velocity and relative humidity were measured; then UTCI and WBGT (wet-bulb globe temperature) indices were calculated. Simultaneously, physiological parameters including systolic and diastolic blood pressure, oral temperature, skin temperature, tympanic temperature and heart rate of workers were measured. UTCI and WBGT indices were $34.2 \pm 2^{\circ} \mathrm{C}, 21.8 \pm 1.8^{\circ} \mathrm{C}$ in the outdoor environments and $38.1 \pm 4.4^{\circ} \mathrm{C}, 24.7 \pm 3.3^{\circ} \mathrm{C}$ at the indoor environments, respectively. There were the weak inverse relationships between UTCI and WBGT indices at the outdoor environments and physiological responses such as systolic blood pressure, and diastolic blood pressure. However, there were no similar results for indoor environments. The significant relationships were found between UTCI and WBGT at both indoor and outdoor environments. Both UTCI and WBGT indices are suitable for assessing the occupational heat stress. Although, UTCI index seems more appropriate for heat stress assessment in the environments with low humidity and air velocity.
\end{abstract}

Key words: Heat stress, Physiological response, UTCI index, WBGT index

\section{Introduction}

The growth and development of technology in workplaces leads to improve productivity and health and welfare of employees. Nevertheless, most of the countries including Iran, still face the occupational health and safety

*To whom correspondence should be addressed. E-mail: fgolbabaei@sina.tums.ac.ir

(C)2016 National Institute of Occupational Safety and Health hazards and work-related diseases and injuries. Brick production industries are one of the most important industrial sectors in Iran, which allocate a high volume of structural productions itself and have employed a large number of workers, who are working in hot indoor and outdoor environments.

Heat stress is represented as a physical harmful agent in the workplaces like mining, agriculture, smelting industries and $\operatorname{etc}^{1,2)}$. Heat Exposure endangers the health and safety of the workers and increases the risk of many 
health problems like heat exhaustion and heat stroke $\mathrm{e}^{3,4)}$. Tawatsupa et al. found that heat stress increases risk of kidney diseases ${ }^{5)}$. Exposure to heat stress can reduce work efficiency and productivity ${ }^{4,6}$. Whereas, heat stress has been recognized as a main harmful factor, it is sometimes neglected ${ }^{7}$.

Heat stress indices as valid tools to conduct a heat stress assessment, are a single number that considers the effects of the basic environmental parameters on human response $^{4)}$. In occupational hygiene, there are different indices to assess heat stress, which some of them is approved by International Standard Organization (ISO) like Wet Bulb Globe Temperature (WBGT) and Predicted Heat Strain (PHS) ${ }^{4,8)}$. WBGT is the most widely used estimator for assessing heat stress in industry and some studies showed good correlation between WBGT and environmental factors ${ }^{1}$. Moreover, physiological parameters such as heart rate, sweat rate, rectal temperature and metabolic rate have been used to evaluate heat stress ${ }^{9)}$.

Monazzam et al. have been found a linear relationship between the heat stress indices including WBGT and DI (Discomfort Index) and physiological parameters in their subjects $^{4)}$.

Universal Thermal Climate Index (UTCI) is a nonoccupational hygiene index to assess heat stress in the outdoor thermal environment for public health purposes $^{10,11)}$. It is recently presented by COST (a European Union program promoting Cooperation in Science and Technology) Action 730 ${ }^{12)}$. UTCI is derived from the most recent scientific progress in human thermo-physiology, in biophysics and heat exchange theory ${ }^{12)}$. UTCI has been used in the numerous community-oriented studies, but its application has not been yet investigated in occupational health issues ${ }^{10,12)}$.

The aim of the present study was to assess the possibility of application of UTCI in occupational heat stress assessment and determine the relationship between UTCI, as an innovative and science-based index in public health researches, and WBGT, as the most applied index for evaluating heat stress in workplaces. Workers of Brick production industries in Shahroud were exposed to both indoor and outdoor heat stress, so it could be possible to investigate the applicability of UTCI for assessing occupational heat stress in both work environments. In addition, Shahroud is a city with a cold desert climate in Semnan Province, Iran. It experiences hot summers, cool winters and low precipitation ${ }^{13)}$.

In order to achieve the mentioned goal, first the WBGT and UTCI indices in workplaces and some physiological parameters of workers were measured, then the correlations between WBGT and UTCI indices were determined and also it was investigated how the intended indices can be correlated with the physiological parameters.

\section{Subjects and Methods}

This descriptive-analytical cross-sectional study was conducted on all workers (totally, 200 men including 104 subjects in outdoors and 96 ones at indoors) of Brick industries of Shahroud, Iran at the end of the summer season.

Environmental parameters, including dry temperature, wet-bulb temperature, globe temperature, relative humidity and air velocity were alternatively measured at workstations from 8.00 am to $14.00 \mathrm{pm}$ by Microtherm Heat Stress system (Casella CEL Inc.) and Air flow meter (PCE-007, PCE Co). WBGT index for indoor and outdoor environment was calculated as follow equations, according to ISO 7243 standard $^{1)}$ :

$$
\mathrm{WBGT}_{\text {(Indoor) }}=0.7 \mathrm{~T}_{\mathrm{nw}} \times 0.3 \mathrm{~T}_{\mathrm{g}} \quad \text { (Eq. 1) }
$$$$
\mathrm{WBGT}_{\text {(outdoor) }}=0.7 \mathrm{~T}_{\mathrm{nw}} \times 0.2 \mathrm{~T}_{\mathrm{g}} \times 0.1 \mathrm{~T}_{\mathrm{a}} \quad \text { (Eq. 2) }
$$

Where, $T_{n w}$ is natural wet-bulb temperature, $T_{g}$ is the black-globe temperature and $T_{a}$ is the natural dry-bulb temperature. UTCI index was calculated by UTCI software (ver. A002) regarding air temperature, mean radiant temperature, wind speed and humidity ${ }^{14}$. The UTCI is defined as the air temperature of the reference condition causing the same model response as actual conditions. This can be shown in general function as follow ${ }^{14)}$.

$\mathrm{UTCI}=\mathrm{f}(\mathrm{Ta} ; \mathrm{Tmrt} ; \mathrm{Va} ; \mathrm{RH})$

Where $T_{a}$ : air temperature, Tmrt: mean radiant temperature, $\mathrm{V}_{\mathrm{a}}$ : wind speed and RH: relative humidity. Tmrt was considered equal to air temperature ${ }^{14)}$.

Simultaneously, physiological parameters including systolic and diastolic blood pressure, heart rate, oral temperature, ear's external skin and tympanic temperature of workers were measured from 8 am to $16 \mathrm{pm}$ by Sphygmomanometer (ALP K2 Co.), Stethoscope (ALP K2 Co.), and Thermometer (DT-01A, Frolic Co.), respectively. Ethical approval was granted by the Research Ethics Committee of Tehran University of Medical Sciences. All statistical analyses were performed using SPSS statistical software (ver. 16). Significance level was set at 0.05 for all statistical analyses.

\section{Results}

The mean \pm SD age of participants was $33.64 \pm 5.73 \mathrm{yr}$ 
Table 1. Measurement results of environmental and physiological parameters

\begin{tabular}{|c|c|c|c|c|c|c|c|}
\hline \multirow{2}{*}{ Environmental factors } & \multirow{3}{*}{$\begin{array}{l}\text { Variable } \\
\text { Dry-bulb temperature }(\mathrm{Ta})\left({ }^{\circ} \mathrm{C}\right)\end{array}$} & \multirow{2}{*}{$\begin{array}{l}\text { Workplace location } \\
\text { Indoor }\end{array}$} & \multirow{2}{*}{$\frac{\mathrm{N}}{96}$} & \multirow{2}{*}{$\frac{\text { Minimum }}{25.4}$} & \multirow{2}{*}{$\frac{\text { Maximum }}{35.5}$} & \multirow{2}{*}{$\begin{array}{l}\text { Mean } \\
30.36\end{array}$} & \multirow{2}{*}{$\frac{\text { Std. Deviation }}{3.33}$} \\
\hline & & & & & & & \\
\hline & & Outdoor & 104 & 24.5 & 31.2 & 28.28 & 1.71 \\
\hline & Globe temperature $(\mathrm{Tg})\left({ }^{\circ} \mathrm{C}\right)$ & Indoor & 96 & 26.0 & 39.5 & 32.32 & 4.87 \\
\hline & & Outdoor & 104 & 25.3 & 35.0 & 31.69 & 2.51 \\
\hline & Wet bulb temperature $(\mathrm{Tnw})\left({ }^{\circ} \mathrm{C}\right)$ & Indoor & 96 & 18.4 & 26.6 & 20.99 & 2.52 \\
\hline & & Outdoor & 104 & 15.6 & 19.8 & 17.69 & 0.87 \\
\hline & Relative humidity (RH) (\%) & Indoor & 96 & 32.0 & 53.3 & 42.04 & 6.82 \\
\hline & & Outdoor & 104 & 22.7 & 40.4 & 30.96 & 4.04 \\
\hline & Air velocity (m/s) & Indoor & 96 & 0.2 & 0.5 & 0.36 & 0.15 \\
\hline & & Outdoor & 104 & 2.0 & 3.0 & 2.38 & 0.49 \\
\hline \multirow[t]{4}{*}{ Heat Stress index } & UTCI $\left({ }^{\circ} \mathrm{C}\right)$ & Indoor & 96 & 32.4 & 45.5 & 38.17 & 4.45 \\
\hline & & Outdoor & 104 & 29.4 & 37.6 & 34.29 & 2.04 \\
\hline & WBGT $\left({ }^{\circ} \mathrm{C}\right)$ & Indoor & 96 & 20.7 & 32.0 & 24.71 & 3.39 \\
\hline & & Outdoor & 104 & 18.5 & 29.0 & 21.88 & 1.89 \\
\hline \multirow[t]{12}{*}{ Physiological parameters } & Heart rate (beat/min) & Indoor & 96 & 60.0 & 120.0 & 79.41 & 19.04 \\
\hline & & Outdoor & 104 & 60.0 & 120.0 & 80.07 & 15.68 \\
\hline & Systolic blood pressure (mmHg) & Indoor & 96 & 90.0 & 150.0 & 114.58 & 13.05 \\
\hline & & Outdoor & 104 & 90.0 & 145.0 & 116.42 & 10.439 \\
\hline & Diastolic blood pressure (mmHg) & Indoor & 96 & 60.0 & 110.0 & 78.96 & 11.33 \\
\hline & & Outdoor & 104 & 7.0 & 95.0 & 79.69 & 16.55 \\
\hline & Oral temperature $\left({ }^{\circ} \mathrm{C}\right)$ & Indoor & 96 & 36.5 & 37.5 & 37.04 & 0.26 \\
\hline & & Outdoor & 104 & 36.2 & 37.5 & 36.82 & 0.29 \\
\hline & Tympanic temperature $\left({ }^{\circ} \mathrm{C}\right)$ & Indoor & 96 & 36.2 & 37.2 & 36.73 & 0.25 \\
\hline & & Outdoor & 104 & 35.7 & 37.1 & 36.55 & 0.32 \\
\hline & Skin temperature $\left({ }^{\circ} \mathrm{C}\right)$ & Indoor & 96 & 36.0 & 37.0 & 36.50 & 0.28 \\
\hline & & Outdoor & 104 & 35.9 & 36.9 & 36.39 & 0.27 \\
\hline
\end{tabular}

(ranged in age from 16 to $60 \mathrm{yr}$ ), body mass index $23 \pm$ $3.86 \mathrm{~kg} / \mathrm{m}^{2}$ and work experience $7.44 \pm 6.93 \mathrm{yr}$. Results of environmental and physiological parameters measurement are presented in Table 1. Environmental parameters including dry, glob and wet temperatures and relative humidity were higher in indoor environment than outdoor; therefore, the higher values of WBGT and UTCI were obtained at indoor. Mean WBGT at both workplace locations was smaller compared to UTCI. However, physiological responses like hear rate and systolic and diastolic blood pressure in outdoor were higher.

Table 2 indicates the relationships which exist between heat stress indices (UTCI and WBGT) and environmental and physiological parameters (Pearson Correlation Coefficient test).

As seen in Table 2, at indoor environment, UTCI is significantly correlated with all environmental parameters. Also, there were the negative correlations between both WBGT and UTCI and air velocity. The highest correlation coefficient has been found between the UTCI and globe temperature and also between WBGT and wet-bulb tem- perature.

In terms of physiological responses, the no significant and weak positive correlations exist between heart rate and oral, tympanic and skin temperatures and the two heat stress indices ( $p$-value $>0.05)$. Systolic and diastolic blood pressures were significantly negatively related to UTCI and WBGT ( $p$-value $<0.05)$.

In outdoor workplaces, UTCI was significantly correlated with environmental parameters. No statistically significant relationship existed between WBGT and air velocity. UTCI has stronger correlation with environmental parameters than WBGT and the strongest relationship was found for UTCI and air temperature which is consistent with Kampmann et $a l^{15)}$. No significant correlations were found between all physiological responses and both WBGT and UTCI and (except for a significant relationship between skin temperature and WBGT). The negative correlations existed between oral, tympanic and skin temperatures with WBGT.

Correlation between WBGT and UTCI in indoor and outdoor places is shown in Fig. 1. Scatterplot shows posi- 
Table 2. Correlations between UTCI \& WBGT and Environmental and Physiological parameters

\begin{tabular}{llcccr}
\hline & \multicolumn{2}{c}{ UTCI $\left({ }^{\circ} \mathrm{C}\right)$} & \multicolumn{2}{c}{ WBGT $\left({ }^{\circ} \mathrm{C}\right)$} \\
\cline { 2 - 6 } Environmental variables & $\mathrm{R}$ & $p$-value & $\mathrm{R}$ & $p$-value \\
\cline { 2 - 6 } Indoor $\left({ }^{\circ} \mathrm{C}\right)$ & 0.815 & $<0.001$ & 0.777 & $<0.001$ \\
$\mathrm{Tg}\left({ }^{\circ} \mathrm{C}\right)$ & 0.983 & $<0.001$ & 0.947 & $<0.001$ \\
& $\mathrm{Tnw}\left({ }^{\circ} \mathrm{C}\right)$ & 0.906 & $<0.001$ & 0.958 & $<0.001$ \\
& Air velocity $(\mathrm{m} / \mathrm{s})$ & -0.818 & $<0.001$ & -0.80 & $<0.001$ \\
\cline { 2 - 6 } & Physiological responses & $\mathrm{R}$ & $p$-value & $\mathrm{R}$ & $p$-value \\
\cline { 2 - 6 } & Heart rate $($ beat $/ \mathrm{min})$ & 0.102 & 0.325 & 0.089 & 0.391 \\
Systolic blood pressure $(\mathrm{mmHg})$ & -0.371 & $<0.001$ & -0.374 & $<0.001$ \\
Diastolic blood pressure $(\mathrm{mmHg})$ & -0.414 & $<0.001$ & -0.419 & $<0.001$ \\
Oral temperature $\left({ }^{\circ} \mathrm{C}\right)$ & 0.02 & 0.848 & 0.058 & 0.573 \\
Tympanic temperature $\left({ }^{\circ} \mathrm{C}\right)$ & 0.126 & 0.223 & 0.092 & 0.372 \\
Skin temperature $\left({ }^{\circ} \mathrm{C}\right)$ & 0.134 & 0.193 & 0.172 & 0.094 \\
\hline Environmental variables & $\mathrm{R}$ & $p$-value & $\mathrm{R}$ & $p$-value \\
\hline Ta $\left({ }^{\circ} \mathrm{C}\right)$ & 0.939 & $<0.001$ & 0.459 & $<0.001$ \\
Tg $\left({ }^{\circ} \mathrm{C}\right)$ & 0.891 & $<0.001$ & 0.561 & $<0.001$ \\
Tnw $\left({ }^{\circ} \mathrm{C}\right)$ & 0.886 & $<0.001$ & 0.555 & $<0.001$ \\
Air velocity $(\mathrm{m} / \mathrm{s})$ & 0.253 & 0.01 & 0.058 & 0.556 \\
\hline Physiological responses & $\mathrm{R}$ & $p$-value & $\mathrm{R}$ & $p$-value \\
\hline Heart rate $($ beat $/ \mathrm{min})$ & 0.008 & 0.939 & 0.113 & 0.255 \\
Systolic blood pressure $(\mathrm{mmHg})$ & 0.125 & 0.207 & 0.116 & 0.242 \\
Diastolic blood pressure $(\mathrm{mmHg})$ & 0.176 & 0.075 & 0.056 & 0.574 \\
Oral temperature $\left({ }^{\circ} \mathrm{C}\right)$ & 0.167 & 0.091 & -0.082 & 0.407 \\
Tympanic temperature $\left({ }^{\circ} \mathrm{C}\right)$ & 0.163 & 0.098 & -0.092 & 0.355 \\
Skin temperature $\left({ }^{\circ} \mathrm{C}\right)$ & -0.039 & 0.692 & -0.284 & 0.004 \\
\hline Outdoor & & & &
\end{tabular}

tive and direct relationships between variables. Analysis of the Pearson $r$ coefficients indicated that there was statistically significant relationships between UTCI and WBGT at indoor environments $(\mathrm{r}=0.971, p$-value $<0.001)$ and in outdoor environment $(\mathrm{r}=0.544, p$-value $<0.001)$. This correlation for outdoor environment is not the same strong as indoor.

\section{Discussion}

Heat stress is one of the most hazardous agents in the workplaces. This is very important issue in a tropical and subtropical region like Shahroud, Iran. As mentioned before, exposure to heat stress has a range of health effects including heat stroke, heat exhaustion, heat cramp, increased risk of kidney diseases, reduced attention and concentration and decreased work efficiency and productivity $^{1,5,16)}$. Periodic assessment of occupational exposure to heat stress is health necessity, so a large number of indices including rational, empirical and direct indices were developed by involved scientists and organization.

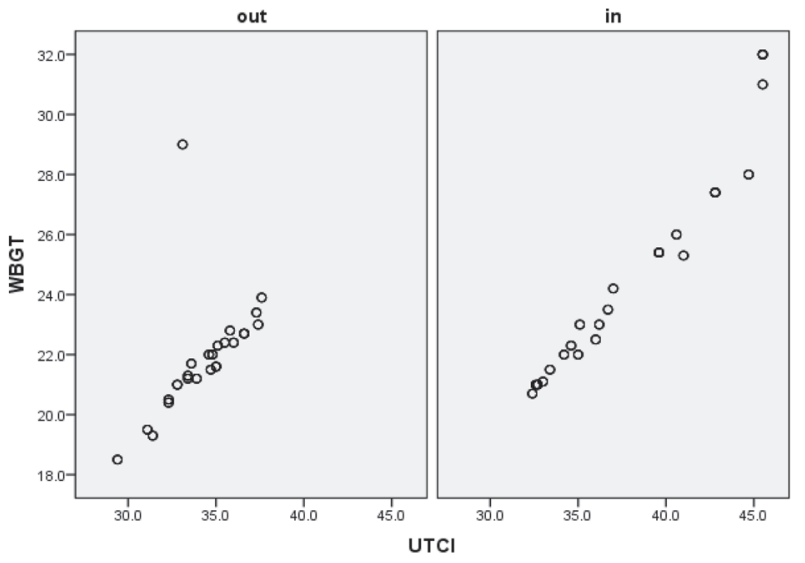

Fig. 1. Scatter plot of Association between UTCI \& WBGT in indoor and outdoor places.

ACGIH (American Conference of Governmental Industrial Hygienists) was determined threshold limit values for occupational exposure to heat stress; regarding WBGT inde ${ }^{4)}$. European COS T Action 730 had put together 
certified experts in the field of human thermophysiology, physiological modelling, meteorology and climatology to develop the UTCI. It is a valid assessment procedure of the outdoor thermal environment considering public weather services, public health systems, urban planning, and climate impact research ${ }^{12,14)}$. Workers of outdoor environments are exposed to heat as the general population as in warm seasons. But in comparison with the general population, they are at a much higher risk due to doing vigorous physical activities which boost their heat production, and working in hot processes. Therefore we aimed to investigate the applicability of this valid tool for thermal environment assessment, UTCI, in occupational heat stress assessment. In Brick production industries in Shahroud, Workers were exposed to both indoor and outdoor heat stress, so it could be possible to investigate the applicability of UTCI in both work environments.

The results of present study indicated that understudy workplaces were hot and dry environment as the mean temperature and relative humidity in outdoor and indoor were $28.29^{\circ} \mathrm{C}, 30.36^{\circ} \mathrm{C}$ and $42.04 \%, 30.96 \%$, respectively. The higher temperature at indoor can result from the presence of the many different heat sources and lack of sufficient ventilation. The higher relative humidity at indoor can be resulted from drying and cooking processes of raw bricks.

There was a noticeable and significant correlation between UTCI and WBGT indices $(r=0.971)$ at indoor environment; however, a moderate correlation existed between them in outdoors ( $\mathrm{r}=0.544)$, but these results have been inconsistent with Blazejczyk et al ${ }^{10)}$. Kampmann et $a l$. found that there are good agreement between UTCI and WBGT for humid conditions and considerably different for low humidity ${ }^{15)}$.

The significant relationships have been found between UTCI and all environmental factors such as air temperature, globe temperature and wet-bulb temperature at both indoor and outdoor environments. Relationship between air velocity and both UTCI and WBGT is negative at indoor and is positive in outdoor. In another word, UTCI which has significant correlation with air velocity for both environments is appropriate for assessing the environments with low air velocity. In line with Brode et al. and Blazejczyk et al. findings, UTCI is less applicable for assessing the environment with high air velocity ${ }^{10,12)}$.

The correlations existed between UTCI and some physiological responses in environments with low air velocity (like understudy indoor environments) confirmed these results, which is in accordance with the work of Blaze- jczyk et $a l^{17)}$. The stronger relationships have been seen between WBGT and indoor environmental parameters including air, glob and wet temperatures, in comparison with outdoors. This finding is consistent with the study of Blazejczyk et al. ${ }^{10)}$, however that is in disagreement with observation of Jay and Kenny ${ }^{6}$. WBGT seems not to be a suitable index for heat stress assessment in areas with higher air velocity and lower relative humidity (like understudy outdoor environments), since in outdoor conditions with less humidity than indoors, there was weaker correlation between WBGT and air velocity. In another words, WBGT index can be strongly not suggested to use for the evaluation of heat stress in areas with low humidity and high air velocity, which is in contrast to the results of Srivastava $e t a l^{7}$.

\section{Conclusion}

In conclusion, the present study illustrates that UTCI, as a heat stress index in public health research showed the high positive correlation with WBGT, as the most applicable index for evaluating heat stress in workplaces. UTCI can be applicable to evaluate heat stresses in the workplaces, especially at indoor environment. In general, UTCI index is appropriate to assess the occupational heat stress in area with low humidity and air movement. Despite all of WBGT' capabilities, there are some limitations for using it for heat stress assessment, and it is claimed that it can provide only a general guide to the likelihood of adverse effects of heat ${ }^{8}$, so more accurate and comprehensive indices of heat stress are required. Here, authors recommend doing further research for assessing the applicability of UTCI, as an innovative and science-based index, in occupational heat stress issues.

\section{Acknowledgement}

The authors wish to express their gratitude to all the subjects who have participated in this study.

\section{References}

1) Golbabaei F, Monazzam MR, Hematjo R, Hosseini M, Farhang Dehghan S (2013) The assessment of heat stress and heat strain in pardis petrochemical complex, Tehran, Iran. IJOH 5, 6-11.

2) Tanaka M (2007) Heat stress standard for hot work environments in Japan. Ind Health 45, 85-90. [Medline] [CrossRef]

3) Haruyama Y, Muto T, Matsuzuki H, Ito A, Tomita S, Muto S, 
Haratani T, Seo A, Ayabe M, Katamoto S (2010) Evaluation of subjective thermal strain in different kitchen working environments using subjective judgment scales. Ind Health 48, 135-44. [Medline] [CrossRef]

4) Monazzam MR, Golbabaei F, Hematjo R, Hosseini M, Nassiri P, Farhang Dehghan S (2014) Evaluation of DI, WBGT and Swreq/PHS heat stress indices for estimating the heat load on the employees of a petrochemical industry. IJOH 6, 6-10.

5) Tawatsupa B, Lim LLY, Kjellstrom T, Seubsman SA, Sleigh A, Thai Cohort Study Team (2012) Association between occupational heat stress and kidney disease among 37,816 workers in the Thai Cohort Study (TCS). J Epidemiol 22, 251-60. [Medline] [CrossRef]

6) Jay O, Kenny GP (2010) Heat exposure in the Canadian workplace. Am J Ind Med 53, 842-53. [Medline]

7) Srivastava A, Kumar R, Joseph E, Kumar A (2000) Heat exposure study in the workplace in a glass manufacturing unit in India. Ann Occup Hyg 44, 449-53. [Medline] [CrossRef]

8) Budd GM (2008) Wet-bulb globe temperature (WBGT) its history and its limitations. J Sci Med Sport 11, 20-32. [Medline] [CrossRef]

9) Brotherhood JR (2008) Heat stress and strain in exercise and sport. J Sci Med Sport 11, 6-19. [Medline] [CrossRef]

10) Blazejczyk K, Epstein Y, Jendritzky G, Staiger H, Tinz B (2012) Comparison of UTCI to selected thermal indices. Int
J Biometeorol 56, 515-35. [Medline] [CrossRef]

11) Langner M, Scherber K, Endlicher WR (2014) Indoor heat stress: an assessment of human bioclimate using the UTCI in different buildings in Berlin. Erde 144, 260-73.

12) Bröde P, Błazejczyk K, Fiala D, Havenith G, Holmér I, Jendritzky G, Kuklane K, Kampmann B (2013) The Universal Thermal Climate Index UTCI compared to ergonomics standards for assessing the thermal environment. Ind Health 51, 16-24. [Medline] [CrossRef]

13) Wikipedia (2014) Shahrud, Iran. http://en.wikipedia.org/ wiki/Shahrud,_Iran. Accessed November 9, 2014.

14) Blazejczyk K, Jendritzky G, Bröde P, Fiala D, Havenith G, Epstein Y, Psikuta A, Kampmann B (2013) An introduction to the Universal Thermal Climate Index (UTCI). Geogr Pol 86, 5-10. [CrossRef]

15) Kampmann B, Bröde P, Fiala D (2012) Physiological responses to temperature and humidity compared to the assessment by UTCI, WGBT and PHS. Int J Biometeorol 56, 505-13. [Medline] [CrossRef]

16) Gaoua N (2010) Cognitive function in hot environments: a question of methodology. Scand J Med Sci Sports 20 Suppl 3, 60-70. [Medline] [CrossRef]

17) Blazejczyk K, Fiala D, Richards M, Rintamäki H, Ruuhela $\mathrm{R}$ (2008) Some features of the human heat balance in winter conditions of polar climate of northern Finland. Probl Klim Pol 18, 89-97 (in Polish). 